\title{
ANALISIS TINGKAT KEBAHAGIAAN PADA LANSIA PENERIMA MANFAAT DAN BUKAN PENERIMA MANFAAT PROGRAM DAY CARE SERVICE
}

\author{
Nur Anna Rakhmadani ${ }^{1}$, Eny Sutria ${ }^{2)}$, Muh. Anwar Hafid ${ }^{3)}$ \\ ${ }^{1,2,3}$ Program Studi Keperawatan S1 Fakultas Kedokteran Dan Ilmu Kesehatan \\ Universitas Islam Negeri Alauddin Makassar \\ e-mail : nurannarachmadani@yahoo.co.id
}

\begin{abstract}
Abstrak
Mengingat pentingnya memberikan pelayanan bagi lanjut usia, panti sosial tresna werdha turut mengelola program day care service, dimana pelayanan ini sangat membantu bagi lanjut usia yang membutuhkan pelayanan untuk menciptakan hubungan sosial. Pelayanan yang diberikan melalui day care service yaitu pelayanan sosial, pelayanan fisik, pelayanan psikososial, pelayanan keterampilan, pelayanan spiritual dan keagamaan serta pemberian bantuan usaha ekonomi. Pelayanan ini sebagai aktivitas untuk meningkatkan produktivitas dalam rangka menambah penghasilan dan sebagai wadah atau fasilitas kegiatan positif dalam pemamfaatan waktu luang lansia.

Desain penelitian yaitu Deskriptif dengan jumlah sampel 88 orang dengan menggunakan purposive sampling dibagi menjadi dua kelompok yaitu 44 orang lansia masing-masing kelompok. Teknik pengumpulan data menggunakan lembar kuesioner kebahagiaan oxford sedangkan analisis yang digunakan dengan Uji Mann Whitney (alpha 0,05)

Berdasarkan hasil penelitian, didapatkan hasil bahwa terdapat perbedaan tingkat kebahagiaan pada lansia penerima manfaat dan bukan penerima manfaat program day care service $(p=0,000)$. Lansia penerima manfaat program day care service dominan memiliki tingkat kebahagiaan yang tinggi dibuktikan dengan jumlah lansia dalam kategori kebahagiaan tinggi 37 orang $(84,1 \%)$ dibandingkan lansia yang tidak menerima manfaat program day care service dibuktikan dengan jumlah 26 orang $(59,1 \%)$. Lansia yang mengikuti day care service mereka mendapatkan dukungan keluarga dan pelayanan dari panti sosial berupa pelayanan fisik, keterampilan, psikososial, spiritual dan keagamaan serta dapat bertemu dengan teman sebaya.
\end{abstract}

Kata kunci: Kebahagiaan Lansia, Day Care Service

\begin{abstract}
Considering the importance of providing services for the elderly, the social institution Tresna Werdha also manages the day care service program, where this service is very helpful for the elderly who need services to create social relationships. Services provided through day care services are social services, physical services, psychosocial services, skills services, spiritual and religious services and providing economic business assistance. This service is an activity to increase productivity in order to increase income and as a place or facility for positive activities in the utilization of leisure time for the elderly.

Research design is descriptive with a sample of 88 people using purposive sampling divided into two groups, namely 44 elderly people in each group. Data collection techniques using oxford happiness questionnaire sheet while the analysis used with Mann Whitney Test (alpha 0.05)

Based on the results of the study, it was found that there were differences in happiness levels in elderly beneficiaries and not beneficiaries of day care service programs $(p=0,000)$. Elderly beneficiaries of the dominant day care service program have a high level of happiness as evidenced by the number of elderly in the category of high happiness 37 people (84.1\%) compared to the elderly who did not receive the benefits of the day care service program as evidenced by the number of 26 people (59.1\%). Elders who attend their day care service get family support and services from social care institutions in the form of physical, skills, psychosocial, spiritual and religious services and can meet with peers.
\end{abstract}

Keywords: Elderly Happiness, Day Care Service 


\section{PENDAHULUAN}

Lanjut usia adalah seseorang yang berada pada tahap usia late adulthood atau dengan kata lain tahap dewasa akhir dengan kisaran usia dari 60 tahun keatas (Widyanto,2014)

Jumlah lansia diseluruh dunia saat ini diperkirakan lebih dari 629 juta jiwa (1 dari 10 orang berusia lebih dari 60 tahun) dan pada tahun 2025 diprediksikan lanjut usia mencapai 1,2 milyar (Sari,2017). World Population Data yang dilansir Population Reference Bereau (PRB) memperkirakan bahwa lansia didunia yang berusia 65 tahun keatas mencapai $8 \%$ dari 7 milyar penduduk dunia atau berjumlah sekitar 564 juta jiwa, sebanyak 53\% dari seluruh penduduk lansia didunia berada di Asia. Sampai sekarang penduduk di 11 negara anggota World Health Organization (WHO) kawasan Asia Tenggara berusia diatas 60 tahun berjumlah 142 jiwa dan diperkirakan akan meningkat hingga 3 kali lipat pada tahun 2050 (WHO, 2012 dalam penelitian Sari, 2017)

Diberbagai Negara, kegiatan pusat pelayanan harian lanjut usia (day care service) dilaksanakan pada jam kerja dan hari senin sampai jumat, dalam lingkungan yang aman, mendukung dan menyenangkan bagi lanjut usia (Kemensos,2015)

Berdasarkan Peraturan Pemerintah (PP) No.43 Tahun 2004 tentang pelaksanaan upaya peningkatan kesejahteraan sosial lanjut usia pasal 1 ayat 4 dan 5 yang menerangkan bahwa kondisi lanjut usia di Indonesia dapat dibedakan menjadi 2 yaitu lansia potensial dan lansia tidak potensial, lansia potensial adalah seseorang yang telah mencapai usia 60 tahun keatas yang masih mampu memenuhi kebutuhannya sendiri baik mampu melakukan pekerjaan dan kegiatan yang menghasilkan barang atau jasa dan tidak bergantung pada orang lain, sedangkan lansia yang tidak potensial adalah seseorang yang berusia 60 tahun keatas yang tidak memiliki kemampuan untuk memenuhi kebutuhannya dan bergantung pada orang lain (Kurniasih,2016).

Hasil Survey Sosial Ekonomi Nasional (susenas) jumlah lansia di Indonesia mencapai 20,24juta jiwa atau setara dengan $8,03 \%$ dari seluruh penduduk Indonesia pada tahun 2014.(Badan Pusat Statistik 2015).
Badan Pusat Statistik (BPS) melaporkan pada tahun 2017 semakin lanjut usia masyarakat di Provinsi Sulawesi Utara (sulut) semakin kurang bahagia. Namun secara nasional penduduk sulut berada di urutan ketiga penduduk paling bahagia, selanjutnya pada subdimensi kepuasan hidup personal nilai indeks semakin menurun seiring dengan bertambahnya usia. Untuk memahami lebih jauh dan membandingkan antara karakteristik yang berkaitan dengan tingkat kebahagiaan, kepuasan hidup, perasaan serta makna hidup maka indeks kebahagiaan Sulawesi Utara disajikan menurut beberapa karakteristik. Kategori karakteristik tersebut adalah klasifikasi wilayah yang mencangkup perkotaan (urban) dan pedesaan (rural), sementara yang lainnya meliputi jenis kelamin, status perkawinan dan kelompok umur. Indeks kebahagiaan Sulawesi Utara tahun 2017 bersdasarkan hasil Survey Pengukuran Tingkat Kebahagiaan (SPTK) sebesar 73.69 pada skala 0-100. Secara nasional penduduk Sulawesi Utara berada di urutan ketiga paling bahagia setelah Maluku Utara dan Maluku (Badan Pusat Statistik,2017)

Di Indonesia, tersedia beberapa jenis sarana pelayanan sosial untuk lanjut usia, meliputi system panti, pelayanan model pendampingan dikalangan keluarga (home care), dan pelayanan harian (day care service) (Wreksoatmodjo,2013).

Salah satu program yang sekarang dilaksanakan oleh pemerintah melalui Kementrian Sosial RI (Kemensos). Direktorat Pelayanan Sosial Lanjut Usia adalah pelayanan harian lanjut usia (PHLU) atau dikenal dengan Day Care. Pelayanan harian lanjut usia merupakan salah satu model pelayanan sosial lanjut usia yang dilaksanakan dalam waktu terbatas (tidak lebih dari 8 jam), tidak menginap serta tidak memisahkan lanjut usia dari keluarga dan masyarakat. Selain itu pelayanan dapat berupa pemberian makanan bergizi dengan memerhatikan lanjut usia yang mempunyai diet khusus serta penyediaan makanan ringan. Penyelenggaraan pelayanan harian lanjut usia/ Day Care dapat juga dilakukan oleh pemerinta atau masyarakat, profit atau nonprofit tujuannya antara lain adalah memberikan peluang kepada lanjut usia untuk melakukan aktivitas di rumah, 
menerima stimulasi mental dan sosial serta menunda atau mencegah institusionalisasi yaitu menunda dan mencegah lanjut usia masuk kedalam pelayanan lembaga melalui penyediaan alternative pelayanan, untuk meningkatkan harga diri dan mendorong lanjut usia untuk bersosialisasi. Pada dasarnya pelayanan harian lanjut usia/ Day Care menyediakan pelayanan aktivitas sosial, makanan, rekreasi dan beberapa pelayanan yang berkaitan dengan kesehatan dasar (Kemensos,2015).

Angka harapan hidup Sulawesi Selatan meningkat cukup signifikan yaitu dari 70,2 tahun pada tahun 2007 menjadi 70,8 pada tahun 2010 (Dinkes Sulawesi Selatan,2012).

\section{METODE PENELITIAN}

Penelitian ini menggunakan desain penelitian Deskriptif dengan pendekatan Cross Sectional. Populasi dalam penelitian ini adalah lansia yang telah mengikuti program day care service diwilayah kerja PSTW Gau Mabaji Gowa dan lansia bukan penerima manfaat day care service didesa pakkatto. Sampel dalam penelitian ini berjumlah 88 orang yang dipilih dengan menggunakan teknik purposive sampling. Purposive sampling adalah suatu tehnik penetapan sampel dengan cara memilih sampel di antara populasi sesuai dengan yang dikehendaki peneliti, sehingga sampel tersebut dapat diwakili karakteristik populasi yang telah dikenal sebelumnya. Analisa menggunakan uji Mann Whitney dengan tingkat kepercayaan 99\%:

1. Kriteria inklusi

a. Lansia yang berusia 60 tahun - 74 tahun

b. Mampu berkomunikasi

c. Sehat fisik dan mental

d. Menikah

2. Kriteria eksklusi
a. Keluarga dan lansia menolak untuk menjadi responden
b. Menderita gangguan jiwa
c. Tidak berada dilokasi pada saat penelitian.

Pengumpulan data pada penelitian ini menggunakan data primer dan sekunder. Data primer yang diperoleh langsung dari subyek yang meliputi umur, tingkat kebahagaiaan dengan cara membagikan kuesioner kepada lansia. Kuesioner ada penelitin ini telh diuji validitas dan reliabilitasnya sert memenuhi standar uji etik. Data sekunder di peroleh dari kepala Desa dan PSTW berupa cakupan lansia di wilayah tersebut.

\section{HASIL}

\section{Karakteristik Responden}

Berdasarkan hasil penelitian yang telah dilakukan, maka didapatkan distribusi jenis kelamin, umur, pendidikan, status pernikahan dan agama. Pada lansia penerima manfaat day care service mayoritas perempuan dengan jumlah 38 orang $(86,4 \%)$, begitu pula dengan lansia di komunitas yang bukan penerima manfaat day care mayoritas perempuan dengan jumlah 35 orang (79,5\%). Berdasarkan pendidikan, lansia penerima manfaat dan lansia yang bukan penerima manfaat day care service mayoritas tingkat pendidikan sekolah dasar (SD) sebanyak 23 orang $(52,3 \%)$ pada lansia penerima manfaat sedangkan lansia yang tidak menerima manfaat day care sebanyak 21 orang $(47,7 \%)$.

Berdasarkan umur lansia, lansia penerima manfaat day care mayoritas berusia 60-65 dengan jumlah 17 orang $(38,6 \%)$, sedangkan lansia yang bukan penerima manfaat mayoritas lansia yang berusia 66-70 tahun dengan jumlah 22 orang (45,5\%). Berdasarkan status pernikahan lansia penerima manfaat maupun lansia yang bukan penerima manfaat day care mayoritas janda/ duda. Adapun berdasarkan agama lansia penerima manfaat dan bukan penerima manfaat day care semuanya beragama islam. Adapun distribusi karakteristik responden dapat dilihat pada tabel 4.1 berikut ini. 


\section{Distribusi Frekuensi Responden}

\begin{tabular}{|c|c|c|c|c|c|}
\hline \multirow{2}{*}{$\begin{array}{l}\text { Karakteristik } \\
\text { Responden }\end{array}$} & & \multicolumn{2}{|c|}{$\begin{array}{l}\text { Lansia penerima } \\
\text { manfaat }\end{array}$} & \multicolumn{2}{|c|}{$\begin{array}{lr}\text { Lansia } & \text { yang } \\
\text { bukan penerima } \\
\text { manfaat }\end{array}$} \\
\hline & & $\mathrm{F}$ & $\%$ & $\mathrm{~F}$ & $\%$ \\
\hline \multicolumn{6}{|l|}{ Jenis kelamin } \\
\hline Laki-Laki & & 6 & 13,6 & 9 & 20,5 \\
\hline \multirow[t]{2}{*}{ Perempuan } & & 38 & 86,4 & 35 & 79,5 \\
\hline & Total & 44 & 100,0 & 44 & 100,0 \\
\hline \multicolumn{6}{|l|}{ Pendidikan } \\
\hline Tidak sekolah & & 11 & 25,0 & 5 & 11,4 \\
\hline SD/ Sederajat & & 23 & 52,3 & 21 & 47,7 \\
\hline SMP/ Sederajat & & 10 & 22,7 & 16 & 36,4 \\
\hline SMA/ Sederajat & & 0 & 0 & 2 & 4,5 \\
\hline \multirow[t]{2}{*}{ Perguruan Tinggi } & & 0 & 0 & 0 & 0 \\
\hline & Total & 44 & 100,0 & 44 & 100,0 \\
\hline \multicolumn{6}{|l|}{ Umur } \\
\hline $60-65$ & & 17 & 38,6 & 7 & 15,9 \\
\hline $66-70$ & & 15 & 34,1 & 20 & 45,5 \\
\hline \multirow[t]{2}{*}{$71-74$} & & 12 & 27,3 & 17 & 38,6 \\
\hline & Total & 44 & 100,0 & 44 & 100,0 \\
\hline \multicolumn{6}{|l|}{ Status Pernikahan } \\
\hline Tidak menikah & & 0 & 0 & 0 & 0 \\
\hline Janda/ duda & & 26 & 59,1 & 29 & 65,9 \\
\hline \multirow[t]{2}{*}{ Nikah } & & 18 & 40,9 & 15 & 34,1 \\
\hline & Total & 44 & 100,0 & 44 & 100,0 \\
\hline \multicolumn{6}{|l|}{ Agama } \\
\hline \multirow[t]{2}{*}{ Islam } & & 44 & 100,0 & 44 & 100,0 \\
\hline & Total & 44 & 100,0 & 44 & 100,0 \\
\hline
\end{tabular}

Sumber: Data Primer 2018 
Analisis Univariat

Analisis univariat menjelaskan tentang distribusi variabel yang meliputi tingkat kebahagiaan rendah, sedang dan tinggi, baik pada lansia penerima manfaat day care dan bukan penerima manfaat. Berdasarkan hasil penelitian disajikan pada tabel 1 tentang analisis univariat menunjukkan bahwa tingkat kebahagiaan lansia terbagi menjadi 3 bagian yaitu rendah, sedang dan tinggi. Dalam penelitian ini terdapat perbedaan tingkat kebahagiaan pada lansia penerima manfaat dan lansia yang bukan penerima manfaat day care service. Tingkat kebahagiaan lansia penerima manfaat day care mayoritas tinggi yaitu 37 orang $(84,1 \%)$ sedangkan lansia dikomunitas yang bukan penerima manfaat day care dengan tingkat kebahagiaan tinggi sebanyak 26 orang $(59,1 \%)$.

Tabel 1. Distribusi Frekuensi Berdasarkan Kebahagiaan Lansia

\begin{tabular}{|c|c|c|c|c|c|}
\hline & & \multicolumn{2}{|c|}{ Penerima manfaat } & \multicolumn{2}{|c|}{ Bukan penerima manfaat } \\
\hline \multicolumn{2}{|c|}{ variabel } & f & $\%$ & f & $\%$ \\
\hline \multicolumn{6}{|c|}{ Kebahagiaan lansia } \\
\hline Rendah & & 0 & 0 & 5 & 11,4 \\
\hline Sedang & & 7 & 15,9 & 13 & 29,5 \\
\hline \multirow[t]{2}{*}{ Tinggi } & & 37 & 84,1 & 26 & 59,1 \\
\hline & Total & 44 & 100,0 & 100,0 & 44 \\
\hline
\end{tabular}

Sumber: $\quad$ Data Primer 2018

Tabel 2. Hasil analisis statistik Kebahagiaan lanjut Usia dengan mann whitney test

\begin{tabular}{|c|c|c|c|c|c|}
\hline Variabel & Median & Min. & Max. & P value & Interpretasi \\
\hline $\begin{array}{l}\text { Kebahagiaan lansia } \\
\text { penerima manfaat day } \\
\text { care service }\end{array}$ & 85,00 & 56 & 87 & & \\
\hline $\begin{array}{l}\text { Kebahagiaan lansia } \\
\text { yang bukan penerima } \\
\text { manfaat day care } \\
\text { service }\end{array}$ & 80,50 & 35 & 87 & 0,0001 & Signifikan \\
\hline
\end{tabular}

\section{PEMBAHASAN}

Analisis univariat menjelaskan tentang distribusi variabel yang meliputi tingkat kebahagiaan rendah, sedang dan tinggi, baik pada lansia penerima manfaat day care dan bukan penerima manfaat. Berdasarkan hasil penelitian disajikan pada tabel 4.2 tentang analisis univariat menunjukkan bahwa tingkat kebahagiaan lansia terbagi menjadi 3 bagian yaitu rendah, sedang dan tinggi. Dalam penelitian ini terdapat perbedaan tingkat kebahagiaan pada lansia penerima manfaat dan lansia yang bukan penerima manfaat day care service. Tingkat kebahagiaan lansia penerima manfaat day care mayoritas tinggi yaitu 37 orang $(84,1 \%)$ sedangkan lansia dikomunitas yang bukan penerima manfaat day care dengan tingkat kebahagiaan tinggi sebanyak 26 orang $(59,1 \%)$.

1. Analisa Bivariat

Dari hasil uji statistic mann whitney tets menyimpulkan bahwa terdapat perbedaan tingkat kebahagiaan lansia penerima manfaat dan lansia yang bukan penerima manfaat program day care service dengan nilai signifikan $(\alpha<0,05)$. Nilai median pada tingkat kebahagiaan lansia penerima manfaat day care 
service 85,00 dengan nilai min yaitu 56 dan max yaitu 87. Sedangkan pada lansia yang tidak menerima manfaat yaitu 80,50 dengan nilai min yaitu 35 dan max yaitu 87 hal tersebut berarti tingkat kebahagiaan lansia yang telah menerima manfaat day care service cenderung lebih tinggi dibandingkan tingkat kebahagiaan pada lansia yang bukan penerima manfaat day care service.

\section{Tingkat Kebahagiaan Lansia Penerima Manfaat dan Bukan Penerima Manfaat}

1. Kebahagiaan penerima manfaat day care service

Berdasarkan hasil penelitian pada lansia penerima manfaat mayoritas pada tingkat kebahagiaan tinggi dengan jumlah 37 orang $(84,1 \%)$, sedangkan pada tingkat kebahagiaan kategori sedang berjumlah 7 orang (15,9\%). Dari hasil observasi selama penelitian lansia penerima manfaat mengungkapkan perasaan bahagia ketika diberi pertanyaan terhadap kondisi yang dirasakan saat ini dan lansia senang mengikuti day care di PSTW Gau Mabaji Gowa, karena selain mendapatkan pelayanan mereka juga dapat berkumpul dengan teman sebaya dan mayoritas responden tinggal dengan keluarganya.

Menurut hasil penelitian yang dilakukan Mastuti (2016) yang berjudul kebahagiaan pada lanjut usia ditinjau dari dukungan keluarga. Hasil menunjukkan bahwa ada hubungan positif yang sangat signifikan antara dukungan keluarga dengan kebahagiaan lansia, dukungan yang diberikan keluarga terhadap kebahagiaan lansia sebesar $47,78 \%$. Maka masih ada 52,22\% factor lain yang berpengaruh terhadap kebahagiaan lanjut usia selain faktor dukungan keluarga.

Pembinaan lansia melalui program day care service ini mampu memberikan perubahan kepada lansia, dimana lansia semangat dalam menjalani hidup, mandiri, terjaga kondisi fisik dan kesehatan, terciptanya tali silaturahmi yang baik, dan lansia mampu memanfaatkan waktu luang.

2. Tingkat kebahagiaan pada lansia bukan penerima manfaat

Berdasarkan hasil penelitian pada lansia bukan penerima manfaat day care service pada kategori tingkat kebahagiaan tinggi berjumlah 26 orang $(59,1 \%)$, sedangkan pada kategori tingkat kebahagiaan sedang berjumlah 13 orang $(29,5 \%)$ menurut peneliti dan hasil observasi selama penelitian mayoritas lansia tinggal bersama dengan keluarga, beberapa lansia mengungkapkan bahwa mereka kurang berinteraksi lagi dengan tetangganya atau teman sebayanya disebabkan faktor kondisi fisik dan terdapat $5(11,4 \%)$ orang lansia dengan tingkat kebahagiaan rendah mengungkapkan mereka kurang mendapatkan perhatian dan perawatan dari anak karena beberapa lansia tinggal terpisah dengan anaknya.

Menurut Mastuti (2016) dukungan keluarga dapat memberikan pengaruh positif terhadap kebahagiaan yang terjadi kepada lansia, dimana seseorang yang telah memasuki usia lanjut akan mengalami perubahan penurunan fungsi kognitif, fungsi fisik, dan fungsi psikis, sehingga lanjut usia membutuhkan perhatian, kenyamanan, dan kasih sayang dari keluarga. Kurangnya perhatian dari keluarga dapat membuat lansia menutup diri dan merasa bahwa ia tidak dihargai. Kebahagiaan lansia akan meningkat ketika lansia mendapatkan pelayanan untuk meningkatkan kualitas hidup menjadi lebih baik, dan hal terbesar yang dapat meningkatkan kualitas hidup lansia adalah membutuhkan perhatian dan penanganan khusus dalam memenuhi kesejahteraannya. Secara psikologis lanjut usia akan merasa bahagia jika memperoleh dukungan sosial yang membuat mereka nyaman, tentram, dan damai dalam menjalani hidup.

Sebagaimana firman Allah dalam Qs Al-luqman $(31: 14)$

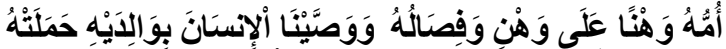

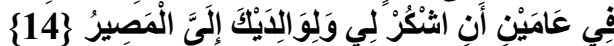

\section{Terjemahnya :}

"Dan kami perintahkan kepada manusia (berbuat baik) kepada kedua orang ibu bapaknya, ibunya yang telah mengandung dalam keadaan lemah yang bertambah-tambah dan menyapinya dalam dua tahun. Bersyukurlah 
kepada-Ku dan kepada kedua drang ibu bapakmu, hanya kepada-kulah kembalimu"

Allah SWT memerintahkan kepada hambah-Nya berbakti kepada orang tua dan memberikan perhatian kepada kedua orang tua. Kandungan di atas diperjelas dalam sebuah hadist, yaitu: "Rasulullah pernah ditanya oleh seorang sahabat: "Amalan apakah yang dicintai oleh Allah? Beliau menjawab: sholat pada waktunya, ia bertanya lagi: kemudian apa? Beliau menjawab: berbuat baik kepada kedua orang tua, ia bertanya lagi: kemudian apa?, Beliau menjawab: Jihad di jalan Allah" (HR Bukhari V/2227, hadist No. 5625)

\section{Pengaruh day care service}

Hasil uji statistic dengan menggunakan mann whitney tets dengan $p$ value 0,000 sehingga dapat disimpulkan bahwa terdapat perbedaan tingkat kebahagiaan lansia penerima manfaat dan bukan penerima manfaat day care service. Kebahagiaan penerima manfaat kategori tinggi berjumlah 37 orang $(84,1 \%)$ sedangkan pada lansia bukan penerima manfaat berjumlah 26 orang $(59,1 \%)$.

Beberapa pelayanan yang diberikan kepada lansia dalam program day care service yaitu:

a. Pelayanan fisik

Pelayanan fisik diberikan kepada peserta day care service dalam rangka memperkuat daya tahan fisik, pelayanan ini diberikan dalam bentuk pelayanan kesehatan fisioterapi, penyediaan menu makanan tambahan, kebugaran, klinik lansia, sarana dan prasaranan sehari-hari dll.

b. Pelayanan sosial

Diberika kepada lansia dalam rangka menciptakan hubungan sosial dan penyesuaian sosial secara serasi dan harmonis diantara lansia, lansia dengan keluarganya dan lansia dengan petugas serta msyarakat sekitar.

c. Pelayanan psikososial

pelayanan ini diberikan kepada peserta dalam rangka menciptakan situasi sosial psikologis yang memungkinkan terciptanya perasaan aman, nyaman, senang dan mampu beradaptasi dengan lingkungan sosialnya. d. Pelayanan keterampilan

Pelayanan inid iberikan tidak saja untuk pengisi waktu luang, melainkan untuk meningkatkan produktivitas agar ia dapat menambah penghasilannya.

e. Pelayanan spiritual dan keagamaan pelayanan ini diberikan dalam rangka memperkuat mental spiritual dan kerohanian terutama dalam melaksanakan aktivitas sehari-hari. Pelayanan yang diberikan antara lain penyediaan sarana dan prasarana ibadah, bimbingan rohani dan lain-lain. Pelayanan spiritual ini sangat penting untuk dilakukan mengingat bahwa pada masa tua seringkali klien berbagai perasaan tidak berharga dan ketakutanketakutan sehubungan dengan penurunan fungsi-fungsi fisik dan sosial. Dengan adanya pelayanan spiritual diharapkan peserta menyadari akan situasi yang dihadapinya sehingga muncul ketenangan dan kedamaian dalam perasaannya. Muncul kembali kepercayaan dirinya, dapat menjalankan ibadah dengan tenang dan tetap dapat beraktivitas sesuai dengan kemampuannya.

f. Pemberian bantuan usaha ekonomi produktif (UEP)

Pelayanan ini diberikan kepada lansia yang membutuhkannya sebagai aktivitas untuk meningkatkan produktivitas dalam rangka menambah penghasilannya (Kemsos,2013).

Pada lansia penerima manfaat mereka mendapatkan pelayanan dari panti salah satunya pelayanan sosial. Dalam penelitian Azwan (2015) dengan judul hubungan dukungan sosial teman sebaya dengan kualitas hidup lansia. Hasil analisa hubungan dukungan sosial teman sebaya terhadap kualitas hidup lansia dengan menggunakan uji Chi-Square menunjukkan $\mathrm{p}$ value sebesar 0,017 dimana $p$ value $<0,05$. Hal ini berarti Ho ditolak dan dapat disimpulkan ada hubungan dukungan sosial teman sebaya terhadap kualitas hidup lansia. Hal ini dapat diartikan bahwa positif atau negatifnya dukungan sosial yang berasal dari teman sebaya mempengaruhi tinggi atau rendahnya kualitas hidup lansia. 
Selain pelayanan sosial program day care service memberikan pelayanan untuk memenuhi kebutuhan lansia agar mampu mengembangkan diri secara produktif, maka diberikan pelayanan seperti pelayanan fisik, pelayanan psikososial, pelayanan keterampilan, pelayanan spiritual dan keagamaan. Hasil penelitian Dian Kurniasih (2016) mendukung hasil penelitian ini bahwa lansia yang mengikuti pembinaan program day care service telah mengalami peningkatan pengetahuan seperti halnya pengetahuan dalam bidang keagamaan, kesehatan, psikologis dan keterampilan. Lansia tetap membutuhkan pendidikan baik itu berupa bentuk pembinaan agar lansia dapat mandiri, berdaya guna dan bahagia. Pembinaan lansia melalui program day care service ini mampu memberikan perubahan kepada lansia, dimana lansia semangat dalam menjalani hidup, mandiri, terjaga kondisi fisik dan kesehatan, terciptanya tali silaturahmi yang baik, dan lansia mampu memanfaatkan waktu luang.

Hasil penelitian yang dilakukan oleh Abdul Asis (2017) yang berjudul Efektivitas Program Day Care Service Terhadap Pelayanan Sosial Lanjut Usia di Panti Sosial Tresna Werdha Gowa, hasil penelitian ini menunjukkan bahwa guna meningkatkan efektivitas program day care service untuk memenuhi kebutuhan lanjut usia agar mampu mengembangkan diri secara produktif, maka dapat dilihat dari jenis-jenis pelayanan yang diberikan yaitu pelayanan sosial, pelayanan fisik, pelayanan psikososial, pelayanan keterampilan,pelayanan spiritual dan keagamaan, serta bantuan usaha ekonomi produktif bagi lansia yang membutuhkan. Adapun upaya untuk meningkatkan pelayanan sosial lansia melalui program day care service yaitu meningkatkan kesehatan fisik dan psikis pada lansia, meningkatkan kemampuan lansia untuk mengembangkan diri dalam menghadapi proses hari tua dan mendorong kemandirian bagi penerima manfaat day care service.

Hasil penelitian Linda (2017) menemukan bahwa motivasi lansia mengikuti program day care service adalah adanya dukungan dari keluarga, perekrutan dan aturan yang sederhana serta lokasi panti dan sarana prasarana yang disediakan, dan lansia mempunyai keinginan untuk bersosialisasi dengan orang lain, dan keinginan lansia untuk memenuhi kebutuhan sekunder akan kegiatan-kegiatan program day care service yang bersifat hiburan.

Berdasarkan hasil penelitian yang telah dilakukan dan beberapa teori pendukung terkait perbedaan tingkat kebahagiaan pada lansia penerima manfaat program day care service dan lansia yang bukan penerima manfaat, peneliti berasumsi empiric bahwa faktor yang dominan paling mempengaruhi kebahagiaan adalah dukungan keluarga, rasa syukur dan hubungan yang baik dengan lingkungan sosial. Pada lansia penerima manfaat program day care service mereka mendapatkan dukungan keluarga dan pelayanan program day care service yang diberikan seperti pelayanan fisik, pelayanan keterampilan, pelayanan psikososial, pelayanan spiritual dan keagamaan serta bantuan usaha ekonomi produktif bagi lansia yang menjadi peserta program day care dan bertemu dengan teman sebaya. Berbeda dengan lansia di komunitas yang bukan pengikuti program day care service yang beberapa hanya mendapatkan dukungan keluarga dan interaksi sosial bagi sebagian lansia, adapun beberapa lansia yang mengatakan hidup mereka kurang bahagia karena merasa kurang mendapatkan perhatian dan perawatan dari keluarga dan faktor ekonomi yang kurang, hal yang di ungkapkan responden selain faktor ekonomi adalah kebahagiaan lansia dipengaruhi factor sosial, dimana lansia mengungkapkan bahwa mereka kurang berinteraksi lagi dengan tetangganya atau orang teman sebayanya disebabkan faktor kondisi fisik.

\section{KESIMPULAN}

Dari hasil penelitian tentang tingkat kebahagiaan lansia penerima manfaat dan bukan penerima manfaat day care service maka dapat disimpulkan yaitu:

1. Tingkat kebahagiaan lansia penerima manfaat program day care service mayoritas tingkat kebahagiaan tinggi sebanyak 37 orang $(84,1 \%)$

2. Tingkat kebahagiaan lansia yang bukan penerima manfaat day care service dalam kategori tinggi sebanyak 26 orang $(59,1 \%)$ 
3. Terdapat perbedaan tingkat kebahagiaan antara lansia penerima manfaat dan bukan penerima manfaat day care service dengan nilai signifikan yaitu 0,000 berarti $\alpha<0,05$.

\section{REFERENSI}

1. Al-Qur,an dan Terjemahannya. Kementrian Agama RI

2. Afdol.2011. Latar Belakang Sosial Ekonomi dan Tingkat Kepuasan Hidup Lanjut Usia Penghuni Panti Werdha. Skripsi PPKP Lemlit Uniar Surabaya.

3. Anggraini, Zulfitri, Novayelinda.2013. Hubungan Status Spiritual Lansia dengan Gaya Hidup Lansia.

4. Asis Abdul.2017. Efektivitas Program Day Care Service Terhadap Pelayanan Lanjut Usia di Panti Sosial Tresna Werdha Gau Mabaji Kabupaten Gowa. Uiniversitas Islam Negeri Alauddin Makassar

5. Agustini Rini \& Hidayah Nur Siti.2012. Kebahagiaan Lansia di Tinjau Dari Dukungan Sosial dan Spiritualitas. Jurnal Soul, Vol 5, No 2, September 2012 https://qjournal.id/jurnal/paper/0008200006/ Kebahagiaan-Lansia-Ditinjau-dariDukungan-Sosial-dan-Spiritualitas

6. Badan Pusat Statistik. 2015. Statistik Penduduk Lanjut Usia 2014. Jakarta. https://www.bps.go.id/publication/2015/11/0 2/e8375b9b7a8e0d380a1fd1da/statistikpenduduk-lanjut-usia-2014.html

7. Badan Pusat Statistik. 2017. Semakin Berusia Lanjut Masyarakat Sulawesi Utara Kurang Bahagai. https://www.antaranews.com/berita/647522/ bps-semakin-berusia-lanjut-masyarakatsulut-makin-kurang-bahagia

8. Dewi, S.R. 2014. Buku Ajar Keperawatan Gerontik. Yogyakarta: Deepublish

9. Dinkes.Sulawesi Selatan.2012. Profil Kota Makassar 2012. Dinas Kesehatan Provinsi.http://dinkeskotamakassar.net/downl oad/3855214Profil\%20Kesehatan\%20Kota\% 20Makassar\%202012.pdf

10.Fuad Muskinul. 2015. Psikologi Kebahagiaan Manusia. STAIN Purwokerto. Jurnal Komunika. Vol.9. No.1

11.Kurniasih Dian.2016. Pembinaan Lanjut Usia Melalui Day Care Service Dibalai
Pelayanan Tresna Werdha Yogyakarta Unit Budi Luhur. Universitas Negeri Yogyakarta

12.Haerul.2015. Riset Keperawatan. Takalar. Pustaka As Asla

13.Hurlock, E.B.2009. Psikologi Perkembangan. Jakartar; Erlangga

14.Hakim Lukmanul dan Hartati Niken.2014. Sumber-Sumber Kebahagiaan Lansia di Tinjau dari Dalam dan Luar Tempat Tinggal Panti Jompo. Jurnal RAP UNP,Vol. 5 No. 1, Mei 2014

15.Isnaeni, Hilda D.2012. Kebahagiaan Lansia yang Tinggal di Panti Werdha.http://eprints.ums.ac.id/20299/1/01.h alaman.depan.pdf

16.Institute for Social and Political Economic Issues.2018. Survei LembagaIndependen ISPEI Menilai Tingkat Kebahagiaan Warga Soppeng Sangat Tinggi. http://www.wanuasulsel.com/2018/01/20/sur vei-lembaga-independen-ispei-menilaitingkat-kebahagiaan-warga-soppeng-sangattinggi/

17.Jenita Doli Tine Donsu. 2016. Metodologi Penelitian Keperawatan. Yogyakarta. Pustaka Baru Pres.

18.Kemsos.2013.Pelayanan Harian Lanjut Usia (Day Care Service) di PSTW Gau MabajiGowa.https://gaumabaji.kemsos.go.id/ modules.php?name $=$ News $\&$ file $=$ article $\&$ sid $=$ 95

19.Kemensos.2015.Pelayanan Harian Lanjut Usia (Day Care). https://rehsos.kemsos.go.id/modules.php?na $\underline{\text { me }=\text { News \& file }=\text { print } \& \text { sid }=1834}$

20.Kurniasih Dian.2016. Pembinaan Lanjut Usia Melalui Day Care Service di Balai pelayanan Sosial Tresna Werdha Yogyakarta Unit Budi Luhur. Skripsi Uneversitas Negeri Yogyakarta. http://eprints.uny.ac.id/35027/1/Dian\%20Ku rniasih_12102244001_0.pdf

21.Lubis Lumongga Namora, Pieter Zan Herri.2010. Pengantar Psikologi dalam Keperawatan. Jakarta. Kencana

22.Linda Susanti.2017. Motivasi Lansia Mengikuti Day Care. Universitas Andalas Padang.

23.Mastuti Dyah Ayu.2016. Kebahagiaan pada lanjut usia ditinjau dari dukungan keluarga. 
Universitas Muhamammadiyah Surakarta. http://eprints.ums.ac.id/47181/7/03.\%20HAL AMAN\%20JUDUL.pdf

24. Muhith Abdul. 2016. Pendidikan Keperawatan Gerontik. Yogyakarta; Cv Andi Offset.

25.Mulyono \& Diponegoro Muhammad Ahmad.2015. Faktor-Faktor Psikologi yang Mempengaruhi Kebahagiaan pada Lanjut Usia Suku Jawa Klaten. Psikopedagogia, Vol 4, No 1, 2015. Universitas Ahmad Dahlan. http://journal.uad.ac.id/index.php/PSIKOPE DAGOGIA/article/download/4476/2506 https://www.researchgate.net/publication/307 085637 Faktor-

Faktor_Psikologis_yang_Mempengaruhi_Ke bahagiaan pada Lanjut Usia Suku Jawa di Klaten

26.Miranti Saharia.2017. Analisis Tingkat Kebahagiaan Lansia di PSTW dan Lansia di Komunitas. Skripsi Universitas Islam Negeri Alauddin Makassar.

27.Maharani Deviana.2015. Tingkat Kebahagiaan (Happiness) pada Mahasiswa Fakultas Ilmu Pendidikan Universitas Negeri Yogyakarta.

http://journal.student.uny.ac.id/ojs/index.php/ fipbk/article/view/186

28. Notoadmojo, S.2010. Metodologi Penelitian Kesehatan. Ed. Revisi. Jakarta. Rineka Cipta

29.Pormanasari,Ria D.2016. Kebahagiaan (Happiness) pada Lansia Muslim di Tinjau dari Partisipasi dalam Aktivitas Keagamaan. Program Studi Psikologi Universitas Muhammadiyah Surakarta. http://eprints.ums.ac.id/44971/1/NASKAH\% 20PUBLIKASI.pdf

30.Puspita Ayu, Dkk.2015. Hubungan Sanse Of Humor Dengan Kebahagiaan Pada Lansia. Fakultas Psikologi Universitas Sumatera Utara. V0.10. N0.1. Hal 25-30.

31.Pali Cicilia.2016. Gambaran Keabahagiaan Pada Lansia yang Memilih Tinggal di Panti Werdha. Jurnal e-Biomedik (eBm), Volume 4, Nomor 1, Januari-Juni 2016. https://media.neliti.com/media/publications/6 2712-ID-gambaran-kebahagiaan-pada-lansiayang-me.pdf
32.Padila.2013.Keperawatan Yogyakarta. Nuha Medika

Gerontik.

33.Rohma Hidayatul Nurul.2013. Hubungan Antara Kepuasan Hidup Remaja dengan Bersyukur pada Siswa SMAIT Abu Bakar Boarding School Yogyakarta. Jurnal Fakultas Psikologi, Vol 2, No 1, Juli 2013

34.Rohmah Dkk.2012. Kualitas Hidup Lanjut Usia. Universitas Airlangga. Vol.3 N0.2, Juli 2012

35.Rahayu Puji Theresia.2016. Determinan Kebahagiaan di Indonesia. Vol XIX No. 1, April 2016. Fakultas Ekonomi dan Bisnis. Unika Atma Jaya Jakarta. http://library.gunadarma.ac.id/journal/view/1 5877/determinan-kebahagiaan-diindonesia.html/

36.Sunaryo dkk.2016. Asuhan Keperawatan Gerontik. Yogyakarta; Cv Andi Offset

37.Sari Triana Mila.2017.Gambaran Kualitas Hidup Lansia di Panti Sosial Tresna Wherda Budi Luhur dan Lansia di Kelurahan Paal V Kota Jambi. Universitas Batanghari Jambi Vol.17 No.2 Tahun.2017. http://ji.unbari.ac.id/index.php/ilmiah/article/ view/371

38.Surtati, E.2014.Mепији Lansia Paripurna.BKKBN

39.Sulandari, S. (2014). Older Indonesians' perceptions of the facilitators of and barriers to optimising their physical activity and social engagement (Thesis tidak dipublikasikan). Faculty of Health Science La Trobe University, Australia

40. Sirojammuniro Anitsnaini.(2015).Kebahagiaan Pada Lanjut Usia yang Tidak Bekerja. Universitas Muhammadiah Surakarta

41.Widyanto Faisal Chandra.2014.Keperawatan Komunitas.Yogyakarta; Nuha Medika.

42.Wreksoatmodjo Riyanto Budi.2013.Perbedaan Karakteristik Lanjut Usia yang Tinggal di Keluarga dengan yang Tinggal di Panti di Jakarta Barat. Vol.40 no.10,th.2013.http://www.kalbemed.com/Por tals/6/07 209Perbedaan\%20Karakteristik\%2 0Lanjut\%20Usia\%20yang\%20Tinggal\%20di $\% 20$ Keluarga $\% 20$ dengan $\% 20$ di $\% 20 \mathrm{Panti} \% 2$ 0di\%20Jakarta\%20Barat.pdf 
43. Yulia Woro Puspitorini.2012. Tingka Laku Proposial dan Kebahagiaan. Skripsi Publikasi: Fakultas Psikologi Universitas Katolik Soegijapranata.

44.Widya.2016. Perbedaan Kualitas Hidup Antara Lansia Yang Tinggal Di Keluarga Dengan Lansia Yang Tinggal di Panti Sosial Tresna Werdha. Universitas Islam Negeri Alauddin Makassar

45.Wenas E, Henry Opod, Cicila Pali.2015. Hubungan Kebahagiaan Dengan Status Ekonomi Keluarga di Kelurahan Artembaga II Kota Bitung. Vol 3. No.1

46.Yuniati Dyah Rosina.2011.Upaya Peningkatan Kesejahteraan Lansia dalam Menghadapi Naiknya Angka Harapan Hidup, Skripsi S1 ilmu FISOPOL UGM. http://etd.ugm.ac.id/index.php?mod=downloa $\underline{\mathrm{d} \& \text { sub=DownloadFile \&act=view \& typ }=\mathrm{html}}$ \&id=79203\&ftyp=potongan \&potongan $=\mathrm{S} 1-$ 2015-299359-chapter1.pdf

47.Zufiana Uun.2014. Meningkatkan Kebahagiaan Lansia di Panti Werdha Melalui Psikoterapi Positif dalam Kelompok. Jurnal Sains dan Praktik Psikologi 2014, Vol 2 (3), 256-267. Universitas Muhammadiyah Malang.http://ejournal.umm.ac.id/index.php/j spp/article/download/2889/3542 